\title{
Study of Charge Compensation During the Redox Process of Self-Doped Polyaniline in Aqueous Media
}

\author{
Hamilton Varela ${ }^{\mathrm{a}}$, Roberto M. Torresi ${ }^{\mathrm{a}^{*}}$ and Daniel A. Buttry \\ a Instituto de Química de São Carlos, Universidade de São Paulo, CP 780, 13560-970, São Carlos - SP, Brazil \\ ${ }^{\mathrm{b}}$ Department of Chemistry, University of Wyoming, Laramie, Wyoming, 82071-3838, USA
}

\begin{abstract}
Um dos problemas mais importantes associado à utilização da polianilina como material catódico em baterias recarregáveis de lítio está relacionado à degradação na densidade de energia devido à participação massiva de ânions durante o processo de compensação de cargas. Este trabalho descreve a síntese de uma polianilina auto-dopada, poli-(anilina-co-N-ácido propanossulfônicoanilina), e avalia suas propriedades em meio aquoso, considerando o aumento na participação de prótons no mecanismo de eletroneutralização. A caracterização foi feita utilizando análise elementar e espectroscopias no infravermelho e ultravioleta-visível. As propriedades eletroquímicas foram investigadas com a microbalança eletroquímica a cristal de quartzo e voltametria cíclica. Os resultados obtidos mostram que a participação de prótons no processo redox da poli-(anilina-co- $\mathrm{N}$-ácido propanossulfônico-anilina) aumentou, em relação à polianilina.
\end{abstract}

One of the most important problems associated with use of polyaniline as a cathode material in rechargeable lithium batteries is related to energy density degradation due to the predomination of anion participation in the charge compensation process. This work describes the synthesis of a selfdoped polyaniline, poly-(aniline-co-N-propanesulfonic acid-aniline), and evaluates its properties in aqueous acid solutions, with special attention to the increase of proton participation in the electroneutralization mechanism. The characterization was carried out using elemental analysis, FTIR and UV-vis spectroscopies. Electrochemical properties were investigated with the electrochemical quartz crystal microbalance and cyclic voltammetry. The results obtained show that proton participation was increased for the redox process of poly-(aniline-co- N-propanesulfonicacid-aniline) in relation to polyaniline.

Keywords: poly (aniline-co-N-propanesulfonic acid-aniline), polyaniline, electrochemical crystal quartz microbalance, charge compensation process, ECQM.

\section{Introduction}

Polymers with $\pi$-conjugated bonds in the chain show uncommon properties like low energy electronic transitions, low ionization potential and high electron affinity. These properties result in polymers that can be oxidized and reduced easily. In order to compensate the charge produced in the polymer matrix by such redox processes, there is usually incorporation/expulsion of ionic species (dopants). Among conducting polymers, polyaniline (PANI) has a prominent role due to its potential applications in energy storage, electrochromic devices, chemical sensors and a series of other electrochemical devices 1,2 . PANI has also been evaluated for use as cathode for rechargeable lithium batteries ${ }^{3}$.

e-mail: Torresi@iqsc.sc.usp.br
The participation of ionic species in the insertion/expulsion process and their influence on the charge compensation mechanism needs to be investigated because this knowledge is of critical importance in the evaluation of PANI as a cathode material for secondary batteries. Ionic transport in the film, necessary to maintain its electroneutrality, has been thoroughly investigated in the case of aqueous solution ${ }^{4-7}$. The main problem related with PANI as a cathode for a lithium battery is the majority participation of anions in the charge compensation process 8 . This fact produces a decrease in the energy density, leading to a power capacity lower than $30 \mathrm{Wh} \mathrm{kg}^{-1}$ for the PANI-Li system ${ }^{9}$. It is obvious that an increase in the energy density can be expected if the polymer uses only cations for the charge compensation process ${ }^{10}$. This conclusion is related to different types of configuration for batteries using conducting polymers as 
cathode. Among the six different configurations for batteries with conducting polymer cathodes 11 , three of them are based on the principle that the cathode uses the cation produced in the anode oxidation to compensate charge. This kind of configuration has the advantage that it does not use a great amount of excess supporting electrolyte so, thin electrolyte films can be used. As a consequence, a diminution in the mass and volume of the battery is obtained. This produces an increase in the specific properties of the battery. Figure 1 shows two different configurations. In Figure 1a, the polymer used as the cathode material might be a material such as PANI, for example, where anions play an important role in charge compensation process and the battery will require an electrolytic reservoir to store anions. In Figure 1b, a polymeric cathode is used where cations are responsible for neutralization process. In this case, the cathode can use the cations produced in the anode, and the described reservoir can be replaced by a thin membrane for cation transport.

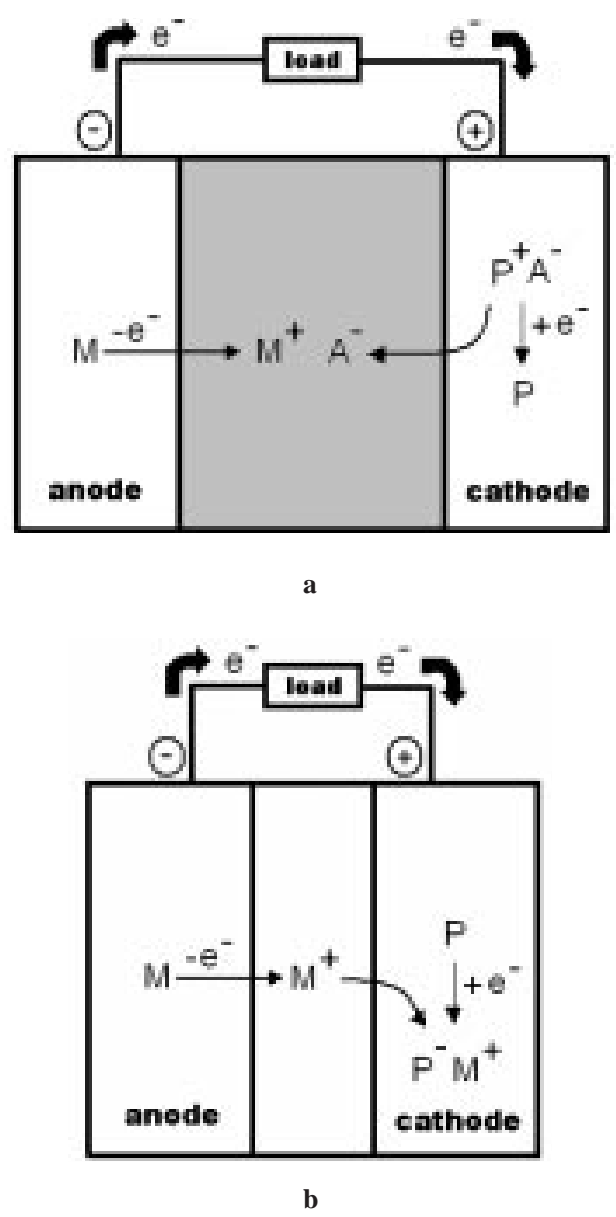

Figure 1. Different configurations for secondary batteries with eletronic conducting polymer as cathode. (a) Charge compensation process carried out by anions and (b) Charge compensation process carried out by cations. Adapted from reference 11 .
It is very important to establish the nature of the ionic exchange and solvent participation in the redox process of conducting polymers in order to choose the best design of the battery, improving in this way their properties. Two alternatives to attempt an increase of the specific properties of PANI for lithium batteries have been studied. First, derivatives obtained by the modification of the original monomer; second, the composites like PANI/NAFION 12 or PANI/DMcT ${ }^{13}$. In this work, the properties of self doped, poly - (aniline - $c o$ - $N$ - propanesulfonic acid - aniline), PAPSAH, were investigated in aqueous media by the use of electrochemical crystal quartz microbalance (ECQM) in conjunction with cyclic voltammetry (CV) experiments. In addition, the synthesis and characterization of PAPSAH are described. For comparison, electrochemically formed PANI films were also investigated. The main purpose is to obtain information about the influence of anionic group (propanesulfonic acid) linked to the polymer chain on the charge compensation process neutralizing the positive charge on the PANI chains.

\section{Experimental}

PAPSAH films were formed by solvent evaporation and PANI films were electrochemically deposited onto Au electrodes supported onto $6 \mathrm{MHz}$ AT cut quartz crystals that were $26 \mathrm{~mm}$ in diameter. A platinum wire was used as counter electrode and all potentials are referred to the saturated calomel electrode (SCE). Both sides of the quartz crystals were coated with gold by vacuum deposition but only one of the faces was exposed to the electrolyte solution (active area of $0.2 \mathrm{~cm}^{2}$ ). The resonance frequency shift was measured with a HP-5370B Universal Time Counter and electrochemical measurements were performed with a FAC 2001 potentiostat/galvanostat.

The electrochemical polymerization of aniline was carried out by cycling the potential between $-0.2 \mathrm{~V}$ and $0.75 \mathrm{~V}$ (versus $\mathrm{SCE}$ ) at $50 \mathrm{mV} / \mathrm{s}$ in a solution of $1 \mathrm{~mol} \mathrm{dm}^{-3} \mathrm{HCl}+$ $0.5 \mathrm{M} \mathrm{C}_{6} \mathrm{H}_{5} \mathrm{NH}_{2}$. All resulting polyaniline films presented good adherence and homogeneity. Films were grown until a net mass gain of $28 \mathrm{mg} \mathrm{cm}^{-2}$ was reached corresponding to a film thickness of $55 \mathrm{~nm}$, determined using a profilometer. After deposition, films were washed carefully with purified water. Electrodes were placed in a usual three-compartment electrochemical cell containing monomer free $1 \mathrm{~mol} \mathrm{dm}^{-3}$ $\mathrm{HCl}$ or $\mathrm{HClO}_{4}$ aqueous solutions.

The method employed for the chemical synthesis of PANI was previously described by Huang et al ${ }^{14}$. An aqueous solution of $\left(\mathrm{NH}_{4}\right)_{2} \mathrm{~S}_{2} \mathrm{O}_{8}$ was added slowly to a solution of aniline dissolved in $1.0 \mathrm{~mol} \mathrm{dm}^{-3}$ aqueous $\mathrm{HCl}$ at $5^{\circ} \mathrm{C}$. After $1 \mathrm{~h}$ the precipitate which had formed was re- 
moved by filtration, washed repeatedly with $1.0 \mathrm{~mol} \mathrm{dm}^{-3}$ $\mathrm{HCl}$ and dried under dynamic vacuum for $48 \mathrm{~h}$. The material thus obtained was identified as emeraldine hydrochloride. The emeraldine hydrochloride was converted into emeraldine base by stirring with $0.1 \mathrm{~mol} \mathrm{dm}^{-3}$ solution of $\mathrm{NH}_{4} \mathrm{OH}$ for several $\mathrm{h}$. The material was dried under dynamic vacuum for $48 \mathrm{~h}$. The lower molar mass species were extracted with $\mathrm{CH} 3 \mathrm{CN}$ until the extract was colourless. The PANI (2.4 g) obtained, in the blue emeraldine base form reacted with an excess $\mathrm{NaH}(1.1 \mathrm{~g})$ in dimethyl sulfoxide (DMSO), at $45^{\circ} \mathrm{C}$ under nitrogen atmosphere for $6 \mathrm{~h}$. The result was a black green solution, in which the original emeraldine base should have been converted to the deprotonated form of the emeraldine base. The resulting solution was reacted with an excess of 1,3 - propanesulfone (4.25 g) for $20 \mathrm{~h}$. at room temperature, yielding a black-blue solution. This solution was precipitated with $1 \mathrm{~mol} \mathrm{dm}^{-3} \mathrm{HCl}$ aqueous solution, the green solid obtained ( $\mathrm{HCl}$ doped PAPSAH) after filtration was washed with a large amount of acetonitrile and then undoped with $\mathrm{NaOH}$ aqueous solution to give a blue solution. This solution, after filtration, was purified by dialysis with semipermeable membrane (Sigma D-9652, molar mass cutoff of 12,400 $\mathrm{g} \mathrm{mol}^{-1}$ ) in purified water (Milli-Q, Millipore), which was replaced with fresh water frequently during 2 days. The poly(aniline-co-sodium N-propanesulfonate-aniline, PAPSANa) aqueous solution obtained was concentrated in a vacuum evaporator (MA 120, Marconi) at a temperature below 50․ The polymer PAPSANa was then converted to poly(aniline-co-N-propanesulfonic acid-aniline, PAPSAH) shown in Figure 2, by exchanging $\mathrm{Na}^{+}$for $\mathrm{H}^{+}$in $\mathrm{H}^{+}$-type ionexchange resin (Dowex 50WX4-100, Sigma) to giveaPAPSAH green coloured aqueous solution (doped state). The modified electrode was obtained by casting this green solution onto the working electrode. The deposited mass was typically $30 \mu \mathrm{g} \mathrm{cm}^{-2}$.

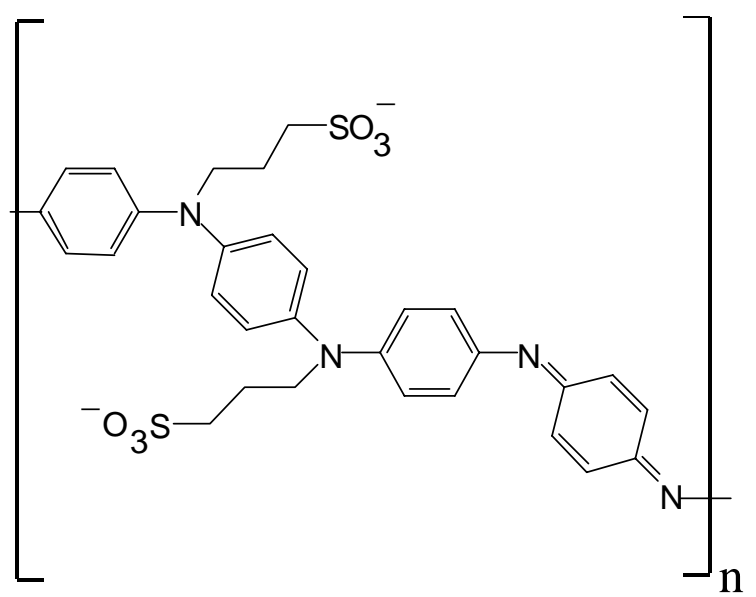

Figure 2. PAPSAH structure.

\section{Results and Discussion}

\section{PAPSAH characterization}

The elemental analysis results are shown in Table 1 . The $\mathrm{S} / \mathrm{N}$ ratio obtained for PAPSAH was 0.55 , close to $0.48 \mathrm{ob}-$ served in previous results 15 , showing that about $50 \%$ of total nitrogen in the chains are linked to alkane sulfonic acid.

Table 1. Elemental analysis results.

\begin{tabular}{lcccc}
\hline Element & $\mathrm{N}$ & $\mathrm{C}$ & $\mathrm{H}$ & $\mathrm{S}$ \\
Mass Percentual & 5.86 & 44.78 & 4.23 & 7.41 \\
\hline
\end{tabular}

Figure 3 shows the FTIR spectra for PANI and PAPSAH. The bands obtained are compared to literature data16-19 in Table 2 showing that the present results agree with those obtained by others authors. The PAPSAH IR spectrum (Figure $3 \mathrm{~b}$ ) shows that the intensity ratio of the peaks at $\sim 1585 \mathrm{~cm}^{-1}$ and $\sim 1500 \mathrm{~cm}^{-1}$ is a qualitative measurement of the oxidation state of the polymer and, in both cases, these ratios show the same oxidation state, indicating an oxidation level of ca 0.8 . The presence of the absorption bands at 1150 and 1034 $\mathrm{cm}^{-1}$ for PAPSAH is characteristic of the asymmetric and symmetric $\mathrm{O}=\mathrm{S}=\mathrm{O}$ stretching vibrations, respectively. Both polymers (Figures $3 \mathrm{a}$ and $3 \mathrm{~b}$ ) present absorption bands at 826 and $821 \mathrm{~cm}^{-1}$, characteristic of the $\mathrm{C}$-H out-of-plane bending vibrations of 1,4 - disubstituted benzene rings. This shows that the reactions used to produce PAPSAH do not lead to ring substitution at other positions. The characteristic band of the secondary aryl amine bending mode $\left(1310 \mathrm{~cm}^{-1}\right)$ confirms that the alkanesulfonic acid groups are linked to the amine nitrogens.

Figure 4 shows UV-vis spectra for PAPSAH aqueous solutions in base and acid forms. The insulator/conductor transition can be discussed in terms of polaron bands, related to base/acid form. The bands located at 400 and 860 $\mathrm{nm}(3,10$ and $1.44 \mathrm{eV})$ are attributed to polaron/bipolaron appearance, and the disappearance of $570 \mathrm{~nm}(2.17 \mathrm{eV})$ band is related to quinoid rings ${ }^{10}$. These results suggest that when PAPSAH is converted from the base to the acid form, there is a strong electronic delocalization, leading to an increase in the mobility of charge carriers.

Redox process (Figure 5a) shows the $\mathrm{j} / \mathrm{E}$ and $\Delta \mathrm{m} / \mathrm{E}$ potentiodynamic profiles of PAPSAH in $\mathrm{HCl}$ electrolytic solution at $50 \mathrm{mV} \mathrm{s}^{-1}$. It can be seen that at the beginning of the oxidation process (between 0 and $0.2 \mathrm{~V}$ ) there is a mass diminution, and at more positive potentials than $0.2 \mathrm{~V}$, the mass increases. This behaviour clearly shows that between 0 and $0.2 \mathrm{~V}$, the electroneutralization in the oxidation 
Table 2. Characteristic bands observed in the FTIR spectrum.

\begin{tabular}{|c|c|c|c|c|}
\hline \multirow[t]{2}{*}{ Characteristic band } & \multicolumn{2}{|c|}{ Pani / $\mathrm{cm}^{-1}$} & \multicolumn{2}{|c|}{ PAPSAH $/ \mathrm{cm}^{-1}$} \\
\hline & Exptl. & Literature ${ }^{15,16}$ & Exptl. & Literature $^{15,16}$ \\
\hline $\mathrm{C}=\mathrm{C}$ quinoid streching & 1583 & 1582 & 1583 & 1592 \\
\hline $\mathrm{C}=\mathrm{C}$ benzenoid streching & 1491 & 1485 & 1498 & 1501 \\
\hline $\mathrm{C}-\mathrm{N}$ secondary aryl amine bending & 1300 & 1311 & 1310 & 1312 \\
\hline $\mathrm{O}=\mathrm{S}=\mathrm{O}$ asymmetric streching & -- & - & 1150 & 1167 \\
\hline $\mathrm{O}=\mathrm{S}=\mathrm{O}$ symmetric streching & -- & -- & 1034 & 1031 \\
\hline C-H out-of-plane bending & 826 & 803 & 821 & 823 \\
\hline
\end{tabular}

process is mainly carried out by proton expulsion, while the incorporation of chloride anions becomes more important at more positive potentials. During the reduction process a mass diminution is observed as a consequence of chloride anion expulsion and proton incorporation.

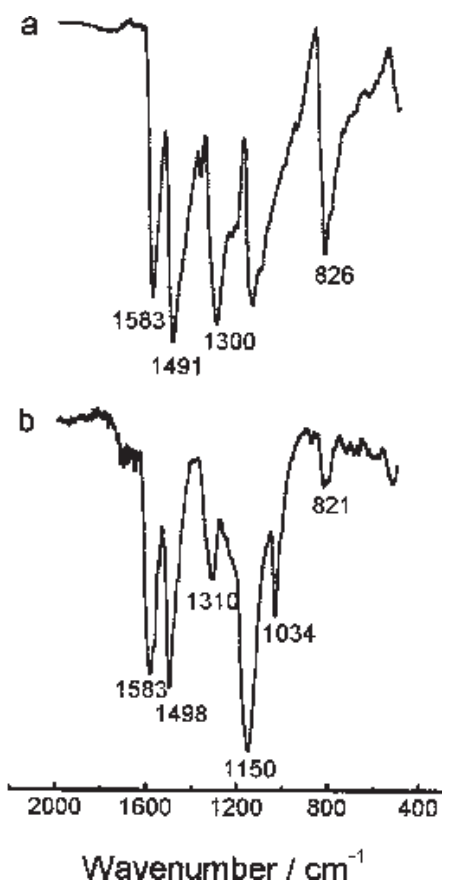

Figure 3. FTIR spectra. (a) PANI and (b) PAPSAH.

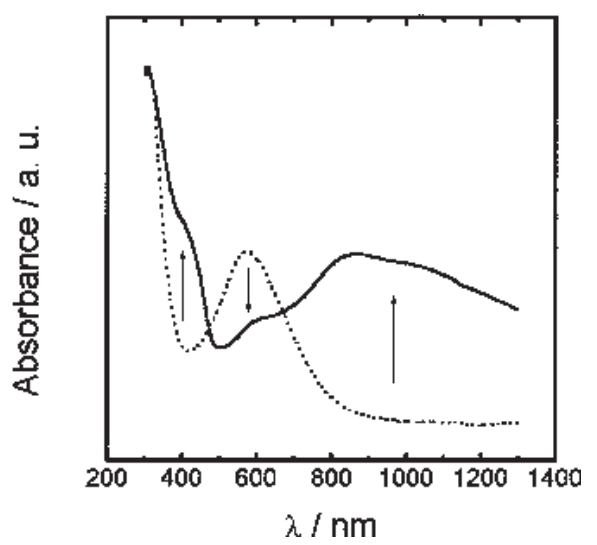

Figure 4. UV-vis spectra for PAPSAH in acid (__ _ $)$ and base $(\cdots \ldots \ldots \ldots \ldots$.$) forms.$
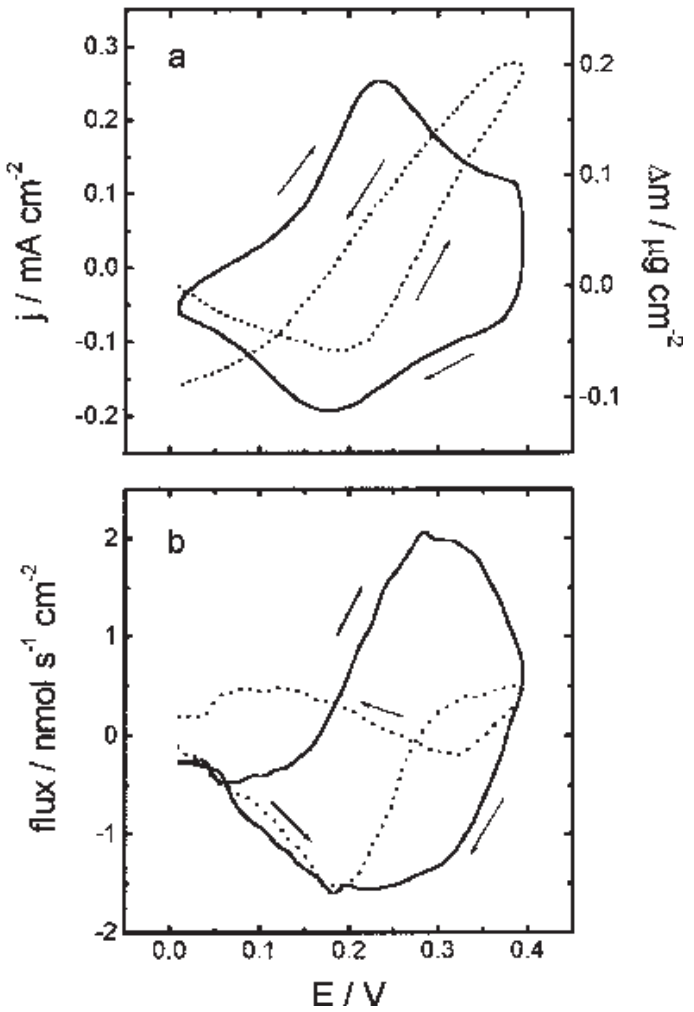

Figure 5. (a) $\mathrm{j} / \mathrm{E}$ ( profiles and (b) proton+solvent $(-(-)$ and anion fluxes (……….....) for PAPSAH in $\mathrm{HCl} 1 \mathrm{~mol} \mathrm{dm}^{-3}$ electrolytic solutions. $\mathrm{v}=50 \mathrm{mV} \mathrm{s}^{-1}$.

In order to analyze the EQCM results in a quantitative form, it is possible to write the global mass change caused by participation of protons, anions and solvent molecules as:

$\Delta \mathrm{m}_{(\mathrm{E})}=\mathrm{W}_{\mathrm{H}^{+}} \xi_{\mathrm{H}^{+}(\mathrm{E})}+\mathrm{W}_{\mathrm{A}^{-}} \xi_{\mathrm{A}^{-}(\mathrm{E})}+\mathrm{W}_{\mathrm{S}} \xi_{\mathrm{S}(\mathrm{E})}$

where $\mathrm{W}$ is the molar mass of protons $\left(\mathrm{H}^{+}\right)$, anions $\left(\mathrm{A}^{-}\right)$or solvent molecules (s) and $\xi$ is the number of moles of of protons, anions or solvent molecules. Considering electroneutralization conditions, the charge involved in the redox process as a function of the number of moles of ionic species can be written as

$\mathrm{q}_{(\mathrm{E})}=-\mathrm{F} \xi_{\mathrm{H}^{+}(\mathrm{E})}+\mathrm{F} \xi_{\mathrm{A}^{-}(\mathrm{E})}$

where $\mathrm{F}$ is the Faraday constant. The charge for protons 
and anions was considered 1 and -1, respectively. Combining equations 1 and 2, the contribution of anions, xA can be calculated together with solvent participation as a function of potential

$\xi_{\mathrm{A}^{-}(\mathrm{E})}+\frac{\mathrm{W}_{\mathrm{S}}}{\mathrm{W}_{\mathrm{HA}}} \xi_{\mathrm{S}(\mathrm{E})}=\frac{\Delta \mathrm{m}_{(\mathrm{E})}}{\mathrm{W}_{\mathrm{HA}}}+\frac{\mathrm{W}_{\mathrm{H}^{+}}}{\mathrm{W}_{\mathrm{HA}}} \frac{\mathrm{q}_{(\mathrm{E})}}{\mathrm{F}}$

In the same way, can be obtained for the protons,

$\xi_{\mathrm{H}^{+}(\mathrm{E})}+\frac{\mathrm{W}_{\mathrm{S}}}{\mathrm{W}_{\mathrm{HA}}} \xi_{\mathrm{S}(\mathrm{E})}=\frac{\Delta \mathrm{m}_{(\mathrm{E})}}{\mathrm{W}_{\mathrm{HA}}}-\frac{\mathrm{W}_{\mathrm{A}^{-}}}{\mathrm{W}_{\mathrm{HA}}} \frac{\mathrm{q}_{(\mathrm{E})}}{\mathrm{F}}$

where HA corresponds to each acid used.

By differentiation of equations 3 and 4 one obtains the flux of protons and anions with a contribution of solvent as a function of the current density and mass flux

$$
\frac{\mathrm{d}\left(\xi_{\mathrm{H}^{+}(\mathrm{E})}+\frac{\mathrm{W}_{\mathrm{S}}}{\mathrm{W}_{\mathrm{HA}}} \xi_{\mathrm{S}(\mathrm{E})}\right)}{\mathrm{dt}}=\frac{1}{\mathrm{~W}_{\mathrm{HA}}} \frac{\mathrm{d}\left(\Delta \mathrm{m}_{(\mathrm{E})}\right)}{\mathrm{dt}}-\frac{\mathrm{W}_{\mathrm{A}^{-}}}{\mathrm{W}_{\mathrm{HA}}} \frac{\mathrm{j}_{(\mathrm{E})}}{\mathrm{F}}
$$

and

$$
\frac{\mathrm{d}\left(\xi_{\mathrm{A}^{-}(\mathrm{E})}+\frac{\mathrm{W}_{\mathrm{S}}}{\mathrm{W}_{\mathrm{HA}}} \xi_{\mathrm{S}(\mathrm{E})}\right)}{\mathrm{dt}}=\frac{1}{\mathrm{~W}_{\mathrm{HA}}} \frac{\mathrm{d}\left(\Delta \mathrm{m}_{(\mathrm{E})}\right)}{\mathrm{dt}}+\frac{\mathrm{W}_{\mathrm{H}^{+}}}{\mathrm{W}_{\mathrm{HA}}} \frac{\mathrm{j}_{(\mathrm{E})}}{\mathrm{F}}
$$

Negative flux values refer to ejection and positive values to incorporation of species in the film. Solvent participation in the process is assumed to be contributing to the observed mass responses when the sign of the flux is contrary to expectations

Figure $5 \mathrm{~b}$ shows the proton and chloride fluxes with the solvent contribution as a function of potential. During the oxidation process, the proton flux shows a maximum at ca $0.18 \mathrm{~V}$ while the chloride flux shows a maximum at ca $0.3 \mathrm{~V}$. This fact clearly demonstrates not only the majority participation of protons at the beginning of the oxidation reaction, but also that the compensation by anions is more important at higher potentials.

Figure 6 a shows the $\mathrm{j} / \mathrm{E}$ and $\Delta \mathrm{m} / \mathrm{E}$ potentiodynamic profiles of PAPSAH in $\mathrm{HClO} 4$ electrolytic solution at 50 $\mathrm{mV} \mathrm{s}^{-1}$. The phenomenological behaviour observed is similar to that obtained for $\mathrm{HCl}$ solutions. However, at the beginning of the oxidation process the loss of mass is smaller than for $\mathrm{HCl}$ solution (see Figure 5a). This fact is a consequence of the greater molar mass of perchlorate, that is to say, even with a reasonable amount of proton expulsion occuring simultaneously with a small amount of perchlorate incorporation, the mass diminution is smaller than in the case of chloride anions. Figure $6 \mathrm{~b}$ shows the proton and perchlorate fluxes with the solvent contribution as a function of potential. The behavior is similar to that observed for chloride solution.

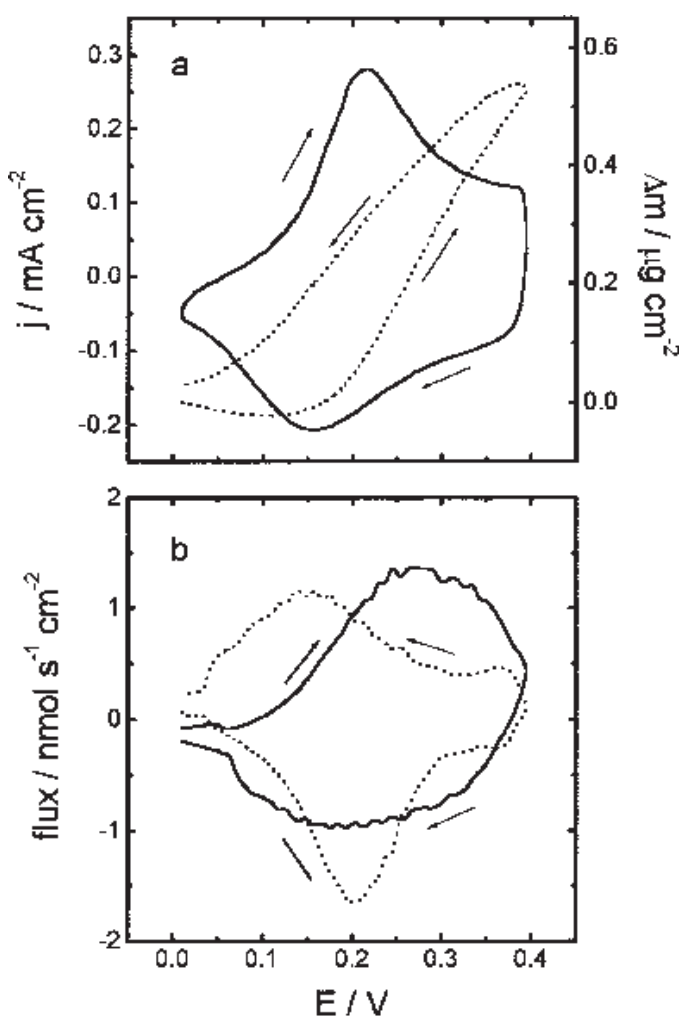

Figure 6. (a) $\mathrm{j} / \mathrm{E}({ }$ ) ) and $\Delta \mathrm{m} / \mathrm{E}(\ldots \ldots \ldots \ldots \ldots)$........) potentiodynamic

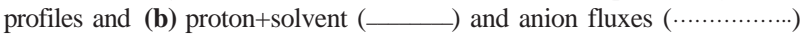
for PAPSAH in $\mathrm{HClO}_{4} 1 \mathrm{~mol} \mathrm{dm}^{-3}$ electrolytic solutions. $\mathrm{v}=50 \mathrm{mVs}^{-1}$.

The proton and anion fluxes also have a solvent contribution. In order to analyze this influence, the ratio of total mass/charge for chloride and perchlorate was calculated. $\left(\Delta \mathrm{m}_{\mathrm{t}} / \mathrm{q}\right.$ ) for chloride solutions was $0.22 \mathrm{~g} / \mathrm{C}$ and for perchlorate solutions was $0.60 \mathrm{~g} \mathrm{C}^{-1}$. The ratio between both values chloride/perchlorate is 0.37 and the ratio between the molar mass of both anions is 0.36 . This shows that the mass changes can be completely accounted for using the molar masses of the anions, and suggests that there is not an important exchange of water molecules during the redox process.

In order to compare the results obtained with PAPSAH, an experiment with PANI was carried out in $\mathrm{HCl}$ solution. Figure $7 \mathrm{a}$ shows the $\mathrm{j} / \mathrm{E}$ and $\Delta \mathrm{m} / \mathrm{E}$ potentiodynamic profiles at $50 \mathrm{mV} \mathrm{s}^{-1}$. The mass profile is similar to that obtained for PAPSAH, showing a mass increase during the oxidation process and a mass diminution during the reduction process. Figure $7 \mathrm{~b}$ shows the fluxes of ionic+solvent species as a function of potential. This Figure shows that 
the charge compensation mechanism is similar in both polymers. At the beginning of the oxidation process there is majority participation of protons and the incorporation of anions becomes more important only at more positive potentials. These results are in agreement with previous results obtained by Buttry et al?.
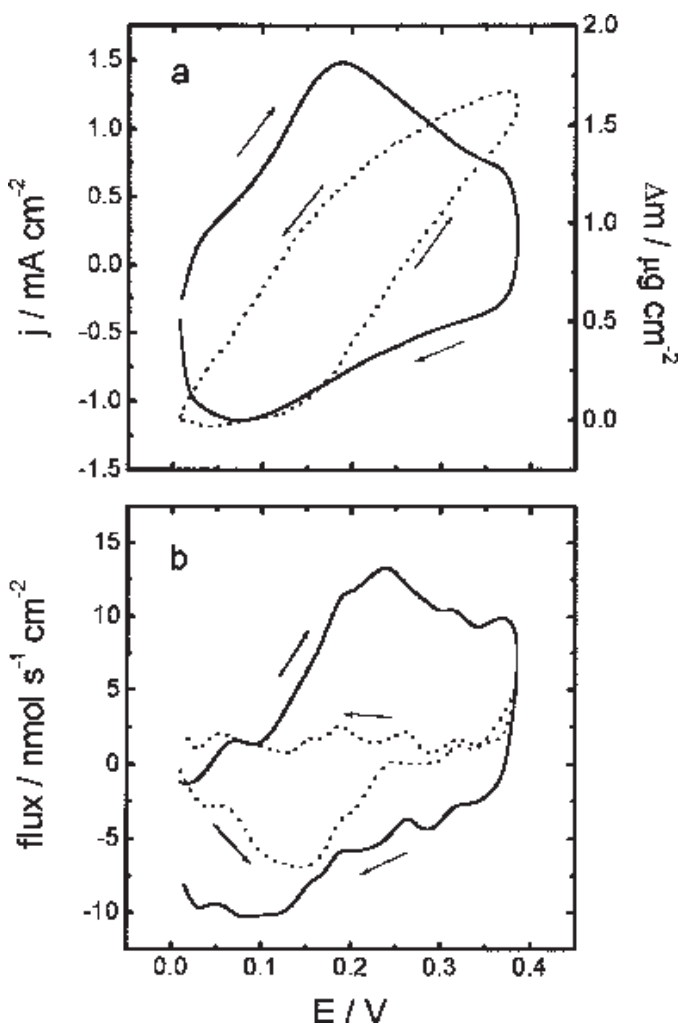

Figure 7. (a) $\mathrm{j} / \mathrm{E}\left({ }_{-}\right)$and $\mathrm{Dm} / \mathrm{E}(\ldots \ldots \ldots \ldots \ldots)$........) potentiodynamic profiles and (b) proton+solvent (_ for PANI in $\mathrm{HCl} 1 \mathrm{~mol} \mathrm{dm}^{-3}$ electrolytic solutions. $\mathrm{v}=50 \mathrm{mVs}^{-1}$.

In order to compare the contribution of anions in both polymers, the transport number of anions as a function of potential for the oxidation process is shown in Figure 8 . The transport number can be calculated using equations 5 and 6 in the case that there is not an important contribution of solvent, so the transport number of protons $\left(\mathrm{t}_{\mathrm{H}+}\right)$ is

$$
\mathrm{t}_{\mathrm{H}^{+}}=\frac{\frac{\mathrm{d} \xi_{\mathrm{H}^{+}}}{\mathrm{dt}} \times \mathrm{F}}{\mathrm{j}}
$$

and the transport number of anions is

$$
\mathrm{t}_{\mathrm{A}^{-}}=\frac{\frac{\mathrm{d} \xi_{\mathrm{A}^{-}}}{\mathrm{dt}} \mathrm{xF}}{\mathrm{j}}
$$

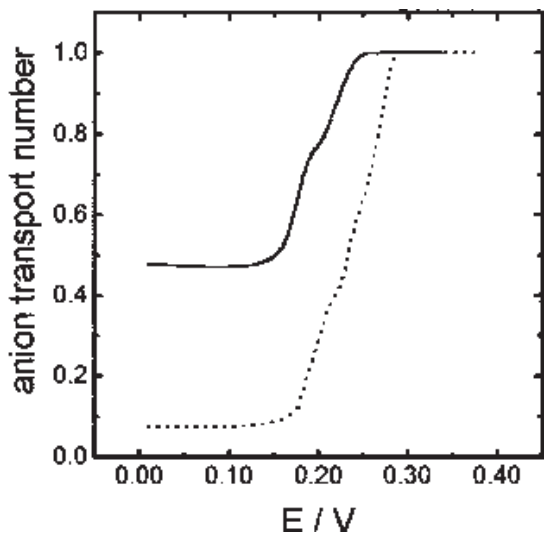

Figure 8 Anion transport number of PANI (__ ) and PAPSAH ( ..............) in $\mathrm{HCl} 1 \mathrm{~mol} \mathrm{dm}^{-3}$ electrolytic solutions. Data calculated from Figures 5 and 7.

The results show that for potentials less positive than $0.2 \mathrm{~V}$ the anion contribution to charge compensation is six times greater for PANI20 than for PAPSAH. Anion contribution increases for both polymers as a function of potential, and finally anions are totally responsible for the charge compensation process (transport number equal to one) in both polymers at sufficiently positive potentials. In this way, funtionalization of the PANI backbone with anionic groups like sulfonate leads to an important improvement of proton contribution to the charge compensation process in specific potential ranges.

\section{Conclusions}

The characterization of PAPSAH is in agreement with reported data in the literature, considering both physical and electrochemical properties. The strategy of comparing the chemically modified polymer PAPSAH with electrochemically formed PANI was very useful as a guide in the properties evaluation. The cation participation during the redox process was increased by between two and six times, depending on the potential region when the water soluble polymer PAPSAH was used. For potentials more positive than $0.25 \mathrm{~V}$, the contribution of anions is the same for both polymers and the transport number equal to 1 , that is to say, that anions are totally responsible for charge compensation process at these potentials.

\section{Acknowledgements}

We are grateful to the Office of Naval Research and the National Science Foundation (INT-9724792), CNPq (910043/ 97-3) and FAPESP (Proc. No 95/0692-0) for support of the work. H. V. thanks FAPESP for the scholarship granted (No 98/00423-7). 


\section{References}

1. Inzelt, G. Electroanalysis, 1995, 7, 895.

2. Scrosati, B. Application of Electroative Polymers; Chapman \& Hall; New York, 1993.

3. Genies, E. M.; Hany, P.; Santier, Ch. J. Appl. Electrochem. 1988, 18, 751.

4. CordobadeTorresi,S.I.; Gabrielli,C.; Keddam,M.; Takenouti, H.; Torresi, R. J. Electroanal. Chem. 1990,290, 269.

5. Torresi, R. M.; Cordoba de Torresi, S. I.; Gabrielli, C.; Keddam, M.; Takenouti, H. Synth. Met. 1993, 61, 291.

6. Bácskai, J.; Kertsész, V.; Inzelt, G. Electrochim. Acta 1993, 38, 393.

7. Orata, D.; Buttry, D. A. J. Am. Chem. Soc. 1987, 109,3574.

8. Desilvestro, J.; Scheifele, W.; Haas, O. J. Electrochem. Soc. 1992, 139, 2727.

9. Barbero, C.; Miras, M. C.; Kötz, R.; Haas, O. Synth. Met. 1993, 55/57, 1539.

10. Barbero, C.; Miras, M. C.; Schnyder, B.; Haas, O.; Kötz, R. J. Mater. Chem. 1994, 4, 1775.
11. Novák, P.; Müler, K.; Santhanam, K. S. V.; Haas, O. Chem. Rev. 1997, 97, 207.

12. Orata, D.; Buttry, D. A. J. Electroanal. Chem.1988, 257, 71 .

13. Oyama, N.; Tatsuma, T.; Sato, T.; Sotomura, T. Nature 1995, 373, 598.

14. Huang, W. S.; Humprey, B. D.; MacDiarmid, A. G. J. Chem. Soc. Faraday Trans. 1986, 1, 2385.

15. Chen, S. A.; Hwang, G. W. J. Am. Chem. Soc. 1994, $116,7939$.

16. Hany, P.; Genies, E. M.; Santier, E. Synth. Met. 1989, 31,369 .

17. Tang, J.; Jing, X.; Wang, B.; Wang, B. Synth. Met. 1988, 24, 231.

18. Chen, S. A.; Hwang, G. W. J. Am. Chem. Soc. 1995 , 117,10055 .

19. Asturias, G. E.; MacDiarmid, A. G.; Maccall, R. P.; Epstein, A. J. Synth. Met. 1989, 29, E157.

20. Daifuku, H.; Kawagoe, T.; Yamamoto, N.; Ohsaka, T.; Oyama, N. J. Electroanal. Chem. 1989, 274, 313.

Received: June 25, 1999

FAPESP helped in meeting the publication costs of this article. 